\title{
High-Pressure Nitrides and Microdiamonds from Tibetan Ophiolite
}

\author{
Mahesh Patil \\ Thane, India \\ Email: mup124@rediffmail.com
}

How to cite this paper: Patil, M. (2019) High-Pressure Nitrides and Microdiamonds from Tibetan Ophiolite. Open Journal of Geology, 9, 1042-1047.

https://doi.org/10.4236/ojg.2019.913104

Received: November 15, 2019

Accepted: December 24, 2019

Published: December 27, 2019

Copyright $\odot 2019$ by author(s) and Scientific Research Publishing Inc. This work is licensed under the Creative Commons Attribution International License (CC BY 4.0).

http://creativecommons.org/licenses/by/4.0/

\begin{abstract}
The samples of microdiamond as an inclusion of Os Ir alloy, coesite, stishovite, high pressure form of $\mathrm{Tio}_{2}$, high pressure nitrides associated with $\mathrm{SiC}$ along with boron carbide, have been reported in the past from the placer deposits of Luobasa ophiolite of Yarlung Zangbo region of Tibet. For the formation of these ultra high findings, pressure in the range of 4 to $9 \mathrm{Gpa}$ and temperature in the range of $700^{\circ} \mathrm{C}-1300^{\circ} \mathrm{C}$ is required. Thus these minerals can either be incorporated into the chromitite in the deep upper mantle or they have an impact origin. In absence of impact crater, Prof. Fang and others have favored the mantle origin but for the formation of nitrides in the deep mantle, the source of $\mathrm{N}$ is not clear. However, the event of comet impact provides better explanation for the formation process. It also simplifies the explanation of coexistence of most of these minerals in a single crystal with the shallow origin and the perfect preservation of the coesite as consequence of rapid cooling after the shock metamorphism.
\end{abstract}

\section{Keywords}

Cubic Boron Nitride, Qingsongite, Boron Carbide, Osbornite, Luobusa Ophiolite, Comet Impact

\section{Introduction}

UHP minerals in the Lubobusa ohphiolite have been a conundrum for some time. Earlier study "Diamond- and Coesite-bearing chromitites from the Luobusa Ophiolite" by Prof. Fang et al. (2007) [1] has expressed the possibility of impact in the formation process but favor mantle origin due to no independent evidence of meteorite impact. The study of Tibetan ophiolite by Prof. Larissa et al. [2] [3] also suggested both the possibilities of impact and mantle origin. However, mantle origin theory has a lot of limitations about the formation 
process of these minerals. Most of these minerals require different depth in the formation process hence their presence in single crystal is difficult to understand. In the event of mantle origin, perfect preservation of coesite crystal looks difficult considering its transportation process to the surface. Mantle origin does not provide any explanation about finds like boron carbide and cubic boron nitride which otherwise are not found in nature. Even low oxygen fugacity of the findings raises many questions about the depth of origin.

Impact event of a comet can provide better explanation for these finds. Comet nuclei are composed of an amalgamation of rock, dust, water ice, frozen carbon dioxide, carbon monoxide, methane, and ammonia. In addition to these gases, the nuclei also contain a variety of organic compounds, which may include methanol, hydrogen cyanide, formaldehyde, ethanol, and other complex molecules such as long-chain hydrocarbons and amino acids. As a result in the event of impact of such body, there is a strong possibility of complex alloy formation. Ammonia can become major source for $\mathrm{N}$ which can lead to formation of ultra high pressure nitrides.

In this study, we are attempting to focus on the possible formation process of UHP minerals in the event of comet impact and will try to explain their co-existence in the single crystal.

\section{Discussions}

\section{1) cubic Boron Nitride (Qingsongite) and its origin}

Reaction for Formation of BN can be depicted as

$$
\mathrm{H}_{3} \mathrm{BO}_{3}+\mathrm{NH}_{3} \stackrel{\Delta}{\longrightarrow} \mathrm{BN}+3 \mathrm{H}_{2} \mathrm{O} .
$$

a) $\mathrm{H}_{3} \mathrm{BO}_{3}$ : Formed from borax, natural Resource at Tibet.

b) $\mathrm{NH}_{3}$ : Part of Comet composition.

c) High Temperature \& Pressure: Result of Impact.

In 2013 International Mineralogical Association Recognized it as only known boron mineral formed in the deep earth mantle found in Luobusha ophiolite of Tibet (Table 1). Boron is rare in the universe, it is formed in minor amounts in cosmic ray spallation and may be found in cosmic dust or meteoroid. Boron is a rare element in the Earth crust $(0.001 \%)$, however it can be highly concentrated by the action of water thus it is found in compounds such as borax, boric acid. Tibet lake region is rich source of borax.

Table 1. Cubic Boron Nitride (Qingsongite) properties.

\begin{tabular}{cc}
\hline Formula & $\mathrm{BN}$ \\
\hline $\begin{array}{c}\text { Crystal System } \\
\text { Pressure }\end{array}$ & Cubic \\
Temperature & Approximately $1300^{\circ} \mathrm{C}-1400^{\circ} \mathrm{C}$ \\
Associated Minerals & Osbornite $(\mathrm{TiN})$, Coesite, Kyanite, Micro diamond with Os, Ir inclusion \\
Occurrence & Luobusa Ophiolite-Tibet
\end{tabular}


Ammonia is a part of Comet composition, hence in the event of comet impact When Boric acid reacts with ammonia at high temperature and UHP above 10 GPa it can form cubic boron nitride. Impact of such nature will lead to transformation of silica and other elements leading to formation of quartz and other complex alloys.

Qingsongite is found in crystal in association with osbornite, Coesite, micro diamond and $\mathrm{Ti}$ rich Kyanite. If we look at the associated minerals that are found with "Qingsongite" then most of these minerals are known for their presence at impact sites. For mantle origin all these elements will require different conditions in the deep earth mantle hence the possibility coexistence in single crystal is difficult to understand. Thus they might have undergone the transformation on the surface itself indicating towards UHP impact in its formation. All these minerals are found in placer deposits which again indicate towards the shallow origin.

\section{2) Boron Carbide:}

Boron carbide is a specially hard material in the group of technical ceramics. This is not naturally available on earth. However, this has been reported from Tibet Ophiolite along with osbornite, coesite, microdiamond and cBN. Boron carbide can be produced by using following reaction at temperature in the range of $1300^{\circ} \mathrm{C}-1400^{\circ} \mathrm{C}$.

a) $4 \mathrm{H}_{3} \mathrm{BO}_{3} \stackrel{\Delta}{\longrightarrow} 2 \mathrm{~B}_{2} \mathrm{O}_{3}+6 \mathrm{H}_{2} \mathrm{O}$.

b) $\mathrm{B}_{2} \mathrm{O}_{3}+3 \mathrm{CO}=2 \mathrm{~B}+3 \mathrm{CO}_{2}$.

c) $4 \mathrm{~B}+\mathrm{C}=\mathrm{B} 4 \mathrm{C}$.

$\mathrm{H}_{3} \mathrm{BO}_{3}$ : Borax is naturally available in Tibet lake region which is the main mineral required for Boric acid.

CO: Solid Carbon Monoxide has been reported from comets. Halley's comet had 15\% CO, Ref. Sekanin (1991) [4].

Thus a comet impact simplifies the formation process and occurrence at impact site.

3) Osbornite ( $\mathrm{TiN})$, Ti rich Kyanite and $\mathrm{TiO}_{2}$ II

Osbornite is very rare natural nitride, originally formed in star dust and now almost exclusively found in meteorites. TiN has been reported from Tibet Ophiolite as natural origin however it provides no explanation on this rare occurrence and coexistence in a crystal which has most of the finds like coesite after stishovite, microdiamonds with OsIr inclusion which are known for impact origin.

Osbornite (TiN): Part of Comet or Result of Nitridation.

The study of star dust from Comet 81 P/wild 2 by Prof. S.B. Simon et al. [5] confirm the presence of $\mathrm{Ti}$ and traces of osbornite (TiN) in comet. The second possibility is nitridation of $\mathrm{TiO}_{2}$. In the event of comet Impact, $\mathrm{TiO}_{2}$ in the presence of ammonia vapors at a temperature in the of $1200^{\circ} \mathrm{C}-1400^{\circ} \mathrm{C}$ will undergo nitridation and form TiN. Because of ammonia Isotopic $\mathrm{N}$ value of this transformed osbornite (TiN) may differ from TiN reported from tail of comet $81 \mathrm{P}$.

Ti Rich Kyanite 
Presence of Ti in comet simplifies exceptional association of Ti rich kyanite reported by Fang et al. (2007) [1] with Raman peak reading not matching any known natural mineral or melt.

$\mathrm{TiO}_{2}$ II

$\mathrm{TiO}_{2} \mathrm{II}$ again is a indicator of either ultra high-pressure or shock induced environment with the temperature in the range of $500^{\circ} \mathrm{C}-1200^{\circ} \mathrm{C}$ and pressure 4 $9 \mathrm{Gpa}$ in the formation process. $\mathrm{TiO}_{2} \mathrm{II}$ was first reported from Ries crater Germany.

\section{4) Microdiamonds and other Minerals}

Microdiamonds along with coesite after stishovite, reported from placer deposits of Yarlung Zangbo region of Tibetan Ophiolite. These samples have shallow origin. These microdiamonds have OsIr inclusion which is a common feature in the impact event. Stishovites are formed at very high shock pressure close to 10 $\mathrm{GPa}$ and temperature in excess of $1200^{\circ} \mathrm{C}$ which is possible in the event of hyper velocity impact. Minerals like $\mathrm{Cr}_{2} \mathrm{O}_{3}$ and $\mathrm{FeO}$ in the chromitite again strengthen the possibility of impact.

Such impact on land will allow UHP phase to have overprinted on the lithosphere. Very high temperature of impact event followed by rapid cooling would lead to encapsulation of the minerals within chromitite resulting in low oxygen fugacity of the material. This also explains the perfect preservation of the coesite as a consequence of such rapid cooling after shock as predicated by Fang et al. (2007) [1].

\section{5) Isotopic Study Of Nitrogen From Comet And Limitations}

In the study of high-pressure nitrides by Prof. Larissa et al. [3] the isotopic value of $\delta^{15} \mathrm{~N}=-10$ which is inconsistent with a continental origin and are slightly more negative than uppermost mantle N. However it also dose not match with $\mathrm{N}$ isotope found in Comet tail. Isotopic study of nitrogen indicates that the comet has different " $N$ " isotope than earth hence in the event of impact origin these nitrides should have an isotopic proposition similar to a comet which is not the case. This contradiction is mainly due to dual source of " $\mathrm{N}$ " in comets.

Current data available for " $\mathrm{N}$ " isotope of comets is of cyanogen molecule (CN, $\mathrm{HCN}$ ) which is found in comet tail. As on date isotopic value of "N" from comet ammonia is not available. Ammonia is a major component of the comet and might have played a key role in the formation of nitrides reported in Tibet. Hence without "N" isotope value of comet ammonia, it will not be appropriate to conduct isotopic comparison basis readings of $\mathrm{CN}$ molecules.

Recent finds of carlsbergite indicate that $\mathrm{Cr}-\mathrm{N}$ was formed in the presence of reactive ammonia present in icy meteorite. Nitrogen Isotopic value of ammonia present in the icy meteorite is similar to Earth's atmospheric nitrogen. In the event of Tibet impact apparently reactive ammonia present in the comet might have played similar role in the formation of UHP nitrides as a result its isotopic $\mathrm{N}$ value is similar to Earth's nitrogen isotope. 


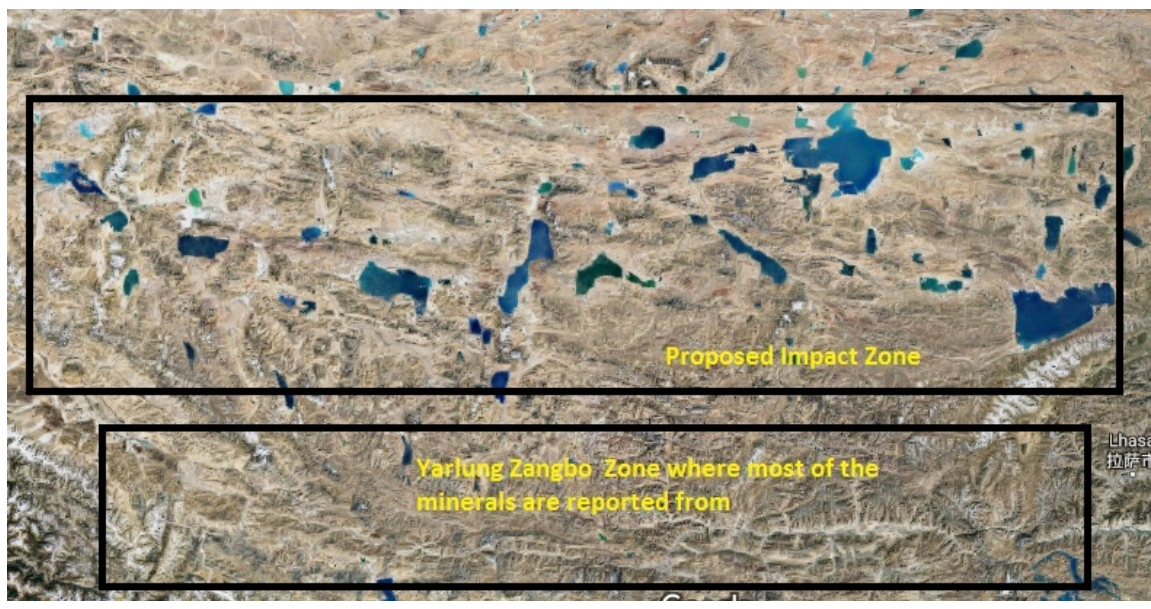

Figure 1. Proposed impact zone and shoemaker Vyas Pattern. Source: Image prepared using google map.

\section{6) Possible Impact Site}

Possibility of disintegrated comet impact in the in the southern Tibet between the latitudes of $82^{\circ}, 30^{\prime} \mathrm{E}$ and $90^{\circ}, 30^{\prime} \mathrm{E}$ and $29^{\circ} \mathrm{N}$ and $33^{\circ} \mathrm{N}$ has been discussed by Patil et al. (6). The study indicates that the lakes (Figure 1) in this region were formed by the impact of a single disintegrating comet that hit the region, which resulted in the unique impact pattern (Shoemaker-Vyas Pattern) spread over a large area. Most of the minerals reported are from the placer deposits in the river beds of Yarlung Zangbo Region of Southern Tibet. These Lakes (craters) in the proposed zone are the main source of water for the Yarlung Zangbo region.

\section{Conclusion}

Most of the UHP phase minerals reported from Tibetan Ophiolite have undergone the transformation on the surface itself. As a result, these minerals have shallow origin with low oxygen fugacity and perfectly preserved coesite. Comet impact provides the explanation of high pressure in excess of $10 \mathrm{GPa}$ and temperature in the range of $1200^{\circ} \mathrm{C}-1300^{\circ} \mathrm{C}$ required in the formation of cubic boron nitride, Stishovite, Osbornite, $\mathrm{TiO}_{2} \mathrm{II}$ and boron carbide. It also explains the source of $\mathrm{N}$ for the formation of nitrides and source of carbon monoxide required for the formation of boron carbide which otherwise can not exist in nature. Further $\mathrm{N}$ isotope study of comet ammonia can help to strengthen the conclusion.

\section{Conflicts of Interest}

The author declares no conflicts of interest regarding the publication of this paper.

\section{References}

[1] Fang, Q.-S., et al. (2007) Diamond- and Coesite-Bearing Chromitites from the Luobusa Ophiolite Tibet. Geology, 35, 875-878. https://doi.org/10.1130/G23766A.1 
[2] Dobrzhinetskaya, L., et al. (2006) Diamond and Coesite after Former Stishovite in Tibet Ophiolite. American Geophysical Union, Fall Meeting, Abstract ID V44B-01.

[3] Dobrzhinetskaya, L.F., et al. (2009) High-Pressure Highly Reduced Nitrides and Oxides from Chromitite of a Tibetan Ophiolite. PNAS, 106, 19233-19238. https://doi.org/10.1073/pnas.0905514106

[4] Sekanina, Z (1991) Sublimation Rates of Carbon Monoxide and Carbon Dioxide from Comets at Large Heliocentric Distances. In Lunar and Planetary Inst., Asteroids, Comets, Meteors, 545-548 (SEE N93-19113 06-90).

[5] Simon, S.B., et al. (2008) A Refractory Inclusion Returned by Stardust from Comet 81P/Wild 2. Meteoritics \& Planetary Science, 43, 1861-1877. https://doi.org/10.1111/j.1945-5100.2008.tb00648.x

[6] Patil, et al. (2018) Disintegrated Comet Trail in Southern Tibet. Open Journal of Geology, 8, 1102-1112. https://doi.org/10.4236/ojg.2018.812067

\section{Appendix}

\section{॥ इदं न मम ॥}

Meaning: "This is not Mine" or "Not my will but Thy will be done". 